Acta Poetica 33•1

ENERO-JUNIO

$2012(49-65)$

\title{
Hacia una pragmática analógica
}

\author{
Mauricio Beuchot
}

En este artículo se intenta plantear la posibilidad de una pragmática analógica, es decir, que tome en cuenta la noción aristotélica de analogía. La analogía se coloca entre la univocidad y la equivocidad, siendo la primera el ideal de lo claro y lo distinto, perfectamente riguroso y exacto; en pragmática es la pretensión del sentido literal pleno. La equivocidad es lo ambiguo e inexacto; en pragmática es la pérdida total del sentido literal. En cambio, la analogía da el sentido de la mediación, tomando de la univocidad la tensión hacia la exactitud y de la equivocidad la apertura, aprovecha sus ventajas, sin caer en los vicios de esos extremos.

Palabras Clave: pragmática, analogía, sentido literal, sentido alegórico, hermenéutica.

This article intends to settle the possibility of an analogical pragmatics, i.e. that takes account of the Aristotelian concept of analogy. Analogy is between univocity and aequivocity, being the first of them the ideal of the clear and distinct, perfectly rigorous and exact; in pragmatics it is the pretension of literal sense. Equivocity is the ambiguous and inexact; in pragmatics it is the total loose of literal sense. Contrary to this, analogy gives the sense of mediation, taking from univocity the tension to exactitude and from equivocity the openness, it profits their advantages, without falling in the vices of those extremes.

KEYwORDs: pragmatics, analogy, literal sense, allegoric sense, herme neutics.

Fecha de recepción: 14 de agosto de 2011

Fecha de aceptación: 23 de septiembre de 2011 

Mauricio Beuchot

Instituto de Investigaciones Filológicas

Universidad Nacional Autónoma de México

\section{Hacia una pragmática analógica}

\section{Introducción}

En este artículo me interesa relacionar la noción de analogía con la pragmática. En otros lugares he estudiado la relación de la analogía con la hermenéutica, en forma de hermenéutica analógica. Convencido de que la hermenéutica y la pragmática coinciden, pienso que puede ser útil conectar la noción de analogía con la pragmática, en forma de pragmática analógica.

Estamos distendidos por las pragmáticas unívocas y las equívocas. Las unívocas pretenden un rigor y una exactitud difícilmente alcanzables; las equívocas se derrumban en la inexactitud y la falta de seriedad. Hace falta un término medio y mediador, y lo puede dar la analogía, que ha sido colocada entre la univocidad y la equivocidad, como un modo de significación intermedio. Por eso intentaré explorar esa relación. Primero hablaré de la pragmática como tal, luego de la analogía y terminaré uniendo esos conceptos como pragmática analógica.

\section{La pragmática y la hermenéutica}

La pragmática es una rama o dimensión de la semiótica. La semiótica es la ciencia general del signo, o del signo en general — no solamente 
del signo lingüístico- (Beuchot, Elementos de semiótica, 12-14). Tiene tres ramas: sintaxis, semántica y pragmática. La sintaxis estudia las relaciones de los signos entre sí, esto es, las relaciones de coherencia. La semántica estudia las relaciones de los signos con los objetos designados, esto es, las relaciones de correspondencia. Y la pragmática estudia las relaciones de los signos con los usuarios, esto es, considera las relaciones de uso. La sintaxis es, entonces, la dimensión más básica e independiente. La semántica supone la sintaxis y se encabalga sobre ella. La pragmática supone las otras dos dimensiones. Por eso esta última es la más compleja y difícil. Tiene que ver con el uso de las expresiones, el cual hace que, para interpretar su significado, haya que atender al contexto (Bertuccelli Papi, Qué es la pragmática, 71 ss.; Escandell Vidal, Introducción a la pragmática, 15-28). Sobre todo cuando el significado padece ambigüedad o equivocidad.

Marcelo Dascal ha dado buenos argumentos para mostrar que la pragmática y la hermenéutica en el fondo coinciden ("Interpretazione ermeneutica e interpretazione pragmática”, 564 ss.). Hay una coincidencia en cuanto a la finalidad. La pragmática busca el significado del hablante (el speaker's meaning), y no el significado como tal (Grice, Significado, 1718). De manera parecida, la hermenéutica busca la intencionalidad del autor, como dice Ricoeur en la línea de la fenomenología ("Philosophie et langage", 452 ss.; "Phenomenology and Hermeneutics", 116). Es decir, ninguna de estas dos disciplinas se queda en el significado como tal (que quizá ni existe), sino que van al significado que surge del uso, según lo que había dicho Wittgenstein: "No me pregunten qué significa una palabra, pregúntenme cómo se usa" (Urmson, El análisis filosófico, 210).

Me parece que la diferencia entre ambas disciplinas proviene del origen. La pragmática surgió de la filosofía analítica, tanto de la vertiente positivista lógica como, por supuesto, de la vertiente pragmática o pragmatista. Eso hace que propenda un tanto al objetivismo (sosteniendo que se puede rescatar el sentido literal). En cambio, la hermenéutica proviene de la fenomenología y, sobre todo, del historicismo y el existencialismo. Por eso propende más al subjetivismo y al relativismo, a veces muy marcado.

La pragmática proviene, en parte, del pragmatismo. Aquí lo trataré en su vertiente norteamericana, pues se dio en otros países, como In- 
glaterra, Francia e Italia. Charles S. Peirce, que fundó el pragmatismo (y que después llamó pragmaticismo), introduce la semiótica (término que toma de Locke), a la cual asigna tres ramas (tomadas del trivium clásico): gramática pura, lógica pura y retórica pura (Collected Papers, 2.229). Charles Morris cambió los nombres a sintaxis, semántica y pragmática, que es como se los conoce ahora (Fundamentos de la teoría de los signos, 36-38).

También el positivismo lógico asumió la semiótica. Notoriamente lo hizo Rudolf Carnap (Beuchot, "Lectura hermenéutica y pragmática", 27 ss.). El proceso o trayectoria de Carnap es muy ilustrativo. Comenzó con la sintaxis, en los años treinta, y publicó La sintaxis lógica del lenguaje (1934). Es una época en la que fue muy duro y tendió a excluir o negar muchas cosas como pseudoproblemas, por ejemplo la metafísica. En los años cuarenta, además de la sintaxis, abordó la semántica, y escribió Introducción a la semántica (1942). Todavía rechazaba la metafísica, pero se lo notaba más abierto que antes. Y después, a finales de los cuarenta y principios de los cincuenta, se abrió a la pragmática, en Significado y necesidad (1949), que incluso lleva un apéndice sobre la pragmática ("On Some Concepts of Pragmatics", 248 ss.), y en "Significado y sinonimia en los lenguajes naturales" (1955) ("Meaning and Synonymy in Natural Languages", 33 ss.). En su última época (muere en 1970), llega a aceptar la metafísica, una interna a las teorías; pero una ontología, al fin y al cabo. Con todo ello se ve cómo va pasando de la sintaxis a la semántica y, finalmente, a la pragmática.

Dentro de la filosofía analítica, después del positivismo lógico (que se dio en el Círculo de Viena, en el Grupo de Berlín y en Inglaterra, con A. J.Ayer), hubo en el ámbito inglés un cambio hacia la pragmática. Se ve ya en el segundo Wittgenstein, que tuvo una gran presencia en Cambridge. Pero también se dio por obra de J. L.Austin. En su obra Cómo hacer cosas con palabras, traza un camino pragmático. Otros más lo siguieron, sobre todo el norteamericano J. Searle. Se atendía a las fuerzas locutivas, ilocutivas y perlocutivas, a lo constativo y a lo performativo (o realizativo), así como a otros aspectos, por ejemplo las implicaturas conversacionales (H. P. Grice), etcétera.

Carnap, que recupera la pragmática, fue amigo de Yeoshua Bar-Hi1lel, con quien incluso escribió una obra en Jerusalén, en 1952: Un es- 
bozo de la teoría de la información semántica, que contiene un proyecto de formalizar la pragmática (Carnap y Bar-Hillel, An Outline of the Theory of Semantic Information, 72 ss.). Bar-Hillel fue maestro de Marcelo Dascal, quien es ahora uno de los mejores exponentes de la pragmática (Pragmatics and the Philosophy of Mind, 18 ss.; Interpretation and Understanding, 54 ss.). Conozco a Dascal y con él he combatido el relativismo extremo (Beuchot, "The Limits of Cultural Relativism: Metaphysics and Latin America", 159 ss.). Esta disciplina semiótica de la pragmática ha tenido un desarrollo muy grande, por ejemplo en Francia, en la escuela de Anscombre.

\section{Los orígenes filosóficos de la pragmática}

En Estados Unidos, la pragmática tuvo su evolución: Peirce, James, Mead, Dewey y sus seguidores. Sidney Hook fue uno de sus más connotados cultores. C.I.Lewis, el gran lógico y pragmatista, fue maestro de Willard Quine, al que legó su pragmatismo. Este último lo mostró con su intento de reducir dicotomías, por ejemplo la de lo analítico y lo sintético, señalándola como uno de los dogmas del empirismo ("Two Dogmas of Empiricism", 20 ss.). Pero otros pragmatistas (ingleses), como Grice y Strawson recuperan la dicotomía de analítico y sintético, alegando que lo analítico se verifica conceptualmente y lo sintético lo hace acudiendo a la experiencia (Grice y Strawson, "In Defence of a Dogma", 141 ss.).

Con todo, a pesar de que había una inclinación al univocismo en la pragmática, especialmente por la influencia neopositivista, también hubo conciencia del peligro de la equivocidad en el significado. Quine lo señaló como las extravagancias de la referencia: la vaguedad, la ambigüedad, la opacidad y, sobre todo, lo que llamó "la inescrutabilidad de la referencia" (Palabra y objeto, 137, 141, 175-176). Donald Davidson, que dependió mucho de Quine, llega a dejar de lado la referencia (Inquiries into Truth and Interpretation, 215 ss., 227 ss.); a pesar de lo cual, Hilary Putnam vuelve a la referencia, pero aduciendo ejemplos de equivocidad que se encuentran en la misma (Representación y realidad, 55 ss.).

En esa lucha entre la univocidad y la equivocidad en la pragmática, ha faltado el tercer elemento: la analogía. Pero tampoco ha estado del 
todo ausente, $\mathrm{y}$ ha habido intentos de una apertura analógica, como en Dewey, Putnam y Searle (Beuchot, "El pensamiento analógico en las filosofías analítica y pragmática", $25 \mathrm{ss}$.). Es el afán de reducir dicotomías. Así, Dewey trató de reducir la dicotomía teoría-praxis; Quine, la de analítico-sintético, y Putnam la de hecho-valor (cosa que también hizo Searle). Sin embargo, Quine fue univocista en ontología, por lo que no puedo ponerlo como analogista.

\section{Sentido literal y sentido alegórico}

Puede decirse que ha habido una lucha, en el seno de la pragmática, entre los literalistas y los alegoristas, de modo parecido a como sucedió en la historia de la hermenéutica. Los que privilegian el sentido literal o por lo menos defienden la posibilidad de rescatarlo, y los que, renunciando al sentido literal, dicen que solamente se puede alcanzar el sentido alegórico de las expresiones.

Marcelo Dascal acepta y defiende el sentido literal, que se puede rescatar si se esfuerza uno lo suficiente ("Una crítica reciente a la noción de significado literal", 33 ss.). También Umberto Eco, notable semiótico pragmatista, defiende el sentido literal; en cambio, otro pragmatista, autodenominado neo-pragmatista, Richard Rorty, rechaza el sentido literal y solo acepta el sentido alegórico ("El progreso del pragmatista", 96 ss.). Hubo una polémica famosa entre los dos.

De hecho, Rorty abandona la filosofía analítica, se denomina postanalítico y neo-pragmatista. Lo llamativo es que se pasa a la hermenéutica. Esto apoya la idea de Dascal de que la pragmática y la hermenéutica coinciden en muchos puntos.

Eco sostiene que se puede captar el sentido literal de un texto, mientras que Rorty dice que solo hay sentido alegórico. Incluso, este último autor llega a decir que los textos no se interpretan, sino que se usan (100-101), cayendo en un pragmatismo excesivo.

Esto se conecta con tres tipos de significación que, desde Aristóteles hasta la actualidad, son el unívoco, el equívoco y al analógico (Aristóteles, Categoriae, I, 1a1-6). El significado unívoco es claro y distinto, tiene una interpretación única y exhaustiva. El significado equívoco es 
oscuro y confuso, tiene el peligro de múltiples interpretaciones, tantas, que se hunde en el relativismo extremo. El significado analógico es intermedio entre los dos anteriores; no tiene la claridad del unívoco, pero tampoco la ambigüedad del equívoco; pero, aun sin ser tan exacto como el unívoco, sirve para hacer ciencia, cosa que no se puede hacer con el equívoco. La univocidad, la equivocidad y la analogía están, pues, presentes en la pragmática. Un ejemplo de término unívoco es "hombre", que se aplica por igual a todos los seres humanos, que cumplan su definición. Un ejemplo de término equívoco es "gato", que se aplica de manera completamente diferente a las cosas que designa, como al animal doméstico, a la herramienta, al juego de niños e incluso a una persona muy servil. Un ejemplo de término análogo o analógico es "ente", que se aplica de manera en parte igual y en parte diferente a la substancia y los accidentes; o "causa", que se aplica de manera en parte igual y en parte diferente a la causa material, a la causa formal, a la causa eficiente y a la causa final; de hecho, los términos filosóficos más importantes no son unívocos, sino analógicos. Por ejemplo, el término "bien", que se divide en bien útil, bien deleitable y bien honesto, o "amistad", que se divide en útil, deleitable y honesta, según Aristóteles.

Atendiendo a estos tres tipos de significar, he hablado de una hermenéutica unívoca, que pretende una única interpretación del texto, completamente literal y rigurosa. Una hermenéutica equívoca sería, al revés, una que se derrumba en muchas interpretaciones del texto, todas ellas válidas y cayendo en un relativismo extremo. Una hermenéutica analógica sabe que no puede pretender la exactitud de la hermenéutica unívoca, mas no por ello se hunde en el relativismo extremo de las interpretaciones, sino que busca una interpretación moderadamente exacta, luchando por no caer en el relativismo equivocista, que de hecho acaba con la hermenéutica, al igual que acaba con ella el absolutismo univocista.

\section{Pragmática unívoca, equívoca y analógica}

Si en la hermenéutica el peligro es la caída en la equivocidad, en la pragmática lo es la propensión a la univocidad. Como hemos visto, la 
hermenéutica equívoca es la que abre demasiado el abanico de las interpretaciones, de modo que casi todas son válidas, dentro de un relativismo excesivo. En cambio, una interpretación univocista es la que pretende una completa objetividad y rigor. Y la pragmática tiende hacia eso, al sostener que se puede recuperar el sentido literal.

Una pragmática unívoca pretende una objetividad radical, un sentido literal, una comprensión exhaustiva. Una pragmática equívoca abandona o rechaza el sentido literal, y solo va al sentido alegórico. Así tenemos en pugna a Eco y a Rorty, el primero defendiendo el sentido literal y el segundo sosteniendo que solo hay sentido alegórico.

A diferencia de las anteriores, una pragmática analógica no busca el sentido literal absoluto, aunque se esfuerza por no perder la tensión hacia él. Y según el texto, se abre hacia la alegoricidad, hacia el sentido alegórico, pero con medida, sin caer en el relativismo de la equivocidad.

En la teoría de los actos de habla, la analogía da una apertura del significado, de modo que los ve desde una teoría de la acción, más abarcadora. En la teoría de la argumentación, la analogía se cumple en la phrónesis o prudencia, que es la que nos hace deliberar para ver los pros y los contras. Es lo que se hace en la retórica, y ella corresponde a la pragmática (Beuchot, La retórica como pragmática y hermenéutica, 133 ss.). Por eso la analogía está muy presente en la pragmática.

Una pragmática analógica es consciente de que en la comunicación se entrometen los intereses particulares, que hay oscuridades y confusiones. Esto lo han señalado Apel y Habermas. Ambos pensadores comenzaron en la hermenéutica, y se pasaron a la pragmática. Apel lo hizo porque consideraba a la pragmática más objetiva ("Respuesta a Mauricio Beuchot", 67 ss.). Eso nos muestra la pretensión de objetividad de la pragmática más allá de la hermenéutica.

Pero, ante todo, la pragmática nos sirve para entender. Una pragmática unívoca, como la de Eco, tiene la pretensión de entender los actos de habla de manera exacta y exhaustiva (sin embargo, el acto de habla tiene casi siempre oscuridades). Una pragmática equívoca, como la de Rorty, se deja hundir en la ambigüedad de las expresiones, desesperando de poder superarla; no alcanza objetividad ni verdad. En cambio, una pragmática analógica trata de entender atendiendo a la oscuridad, reconociéndola, sabiendo que no se va a alcanzar sino pocas veces el sentido 
literal, pero sin derrotarse en un sentido puramente alegórico y oscuro. Es la aceptación del claroscuro de la comunicación, salvaguardando, sin embargo, lo que hay de luminosidad en ella.

Una pragmática analógica atiende sobre todo a la fuerza perlocutiva, además de atender a la ilocutiva. La retórica tenía como propia la elocutio, de la cual está tomada la fuerza ilocutiva; eso muestra que la retórica funcionaba como pragmática, según supo verlo Peirce. Además, una pragmática analógica va más a lo performativo que a lo constativo, aunque trata de no desatender ese aspecto suyo. De hecho, trata de mantener siempre el equilibrio.

Así, la analogía da apertura. Atendiendo a estas fuerzas latentes en los enunciados es como Searle supera la falacia naturalista, y saca el debe del es. Interpretar para valorar, esto es, valorar para superar la interpretación, para ir más allá (“Derivación de 'debe’ a partir de 'ser”, 178 ss.).

\section{El tema de la verdad}

Para tener un ejemplo de cómo puede ser de utilidad la idea de la analogía para la pragmática, veamos uno de los problemas claves, que es el de la verdad. Ya muchos no se atreven a hablar de la verdad en la interpretación, ni pragmática ni hermenéutica. Pero es que conciben la verdad de manera unívoca, la cual resulta las más de las veces inalcanzable, como una adecuación perfecta entre el enunciado y el hecho; es más conveniente hablar de una verdad analógica (por supuesto que no equívoca, la cual dejaría de ser verdad, no alcanzaría ni a ser verosimilitud, y la verdad analógica está más en la línea de la verosimilitud).

En la línea pragmatista, Rorty rechaza la idea tradicional de la verdad ("El mundo felizmente perdido", 60 ss.). Abandona la verdad como adecuación y la abre para que acoja la praxis. Deja el humanismo y pasa al humanitarismo. Por esa apertura, dice que es demócrata, no solo en sentido político, sino cultural, profesa un pluralismo. Deja la epistemología y la metafísica, no pretende esencias ni verdades. Se va a la interpretación, que comparten el pragmatismo y la hermenéutica. Busca una filosofía edificante, en el sentido de edificarnos y edificar a la sociedad o a la comunidad. 
En la línea pragmatista, Rorty da más valor al modo de decir que a lo que se dice. Parece hacer hincapié en la retórica. No renuncia al principio de no contradicción ni al principio del silogismo, sino recalca la apertura hacia la praxis. Antes conocer era edificarse como ser humano, pero ahora Rorty prefiere abrir la posibilidad de la convivencia, edificar la comunidad. Le interesa la conversación, el diálogo edificante. Es el que hace que convivamos. No para hacer un sistema, sino una democracia. No una pragmática universal ni una hermenéutica trascendental, como pretendieron Apel y Habermas, sino algo más modesto, para interpretar lo cotidiano, lo que nos sirve para vivir y convivir.

Es curioso ver que Rorty siempre estuvo combatiendo las ideas de referencia y verdad. Para ello se valía de la semántica de Davidson, que negaba la referencia y, por tanto, la verdad como adecuación. Hasta poco antes de su muerte minó la idea de verdad. Él murió en mayo de 2007, y en enero de ese año dictó en el Instituto de Investigaciones Filosóficas de la Universidad Nacional Autónoma de México unas conferencias en las que seguía hablando de la verdad. Dan ganas de hacer el comentario que hizo Russell en su prólogo al Tractatus logico-philosophicus de Wittgenstein, con su fino humor inglés: "Wittgenstein encuentra el modo de decir una buena cantidad de cosas sobre aquello de lo que nada se puede decir" ("Introducción”, 27). Así, Rorty se pasó la vida hablando de la verdad, diciendo que no nos preocupáramos por ella.

Sin embargo, Rorty no desbancaba sin más la verdad como adecuación, sino que la supeditaba a la creatividad. No negaba que el asesino haya sido el mayordomo, como en las novelas, sino que sostenía que hay algo más importante que esa verdad tan trivial, y que reside en lo que se añade al crear nuevos lenguajes (Contingencia, ironía y solidaridad, 25). Según él, la misma moda filosófica indica que algunos lenguajes quedan atrás, porque no rinden ya, y dan paso a nuevos lenguajes que dan mejor cuenta de los fenómenos que emergen.

Pues bien, una pragmática analógica se coloca entre Quine y Rorty. El primero fue célebre por su univocismo con respecto al término "ser" ("On what there is", 13). Si este término puede tener significado, será un solo significado, que él caracterizaba de la siguiente manera: "ser es ser el valor de una variable ligada" (15). El significado de "ser" era el mismo para todos los seres, como si no hubiera entre ellos notables diferencias, 
por ejemplo entre el ser substancial y el accidental, o entre el concreto y el abstracto, etc. En cambio, Rorty abrió tanto la interpretación, al borrar la referencia (al revés de Quine, que era referencialista, aunque aceptaba opacidades en ella y más bien huía del sentido, entendido como intensión), que se colocó del lado de una pragmática equivocista. En cambio, una pragmática analógica puede recuperar cierta referencia, pero no una referencia unívoca, sino una referencia analógica, con diferencias y matices.

He dicho que Davidson negaba la referencia, pero también rechazaba el sentido como concepto o idea, en una pragmática demasiado conductista ("Respuesta a Mauricio Beuchot", 77 ss.). En la línea pragmática de la teoría de los actos de habla de Austin, Peter Frederick Strawson rechazaba igualmente la verdad como correspondencia, y defendía una verdad como mero consenso, bastante inaceptable, según mi modo de ver ("Respuesta a Mauricio Beuchot", 181 ss. Allí dice que es más realista de lo que yo lo hago). En esa misma línea pragmatista, Larry Laudan posterga la noción de verdad y privilegia la de rendimiento científico ("Respuesta a Mauricio Beuchot", 308-309). Como se ve, hay una tensión entre el referencialismo y el antirreferencialismo, pero es que se ha entendido la referencia como unívoca; y, ya que es difícilmente alcanzable, se pasa a negarla (que es lo más fácil y cómodo); pero creo que no se negaría si no se entendiera como unívoca, sino como analógica.

En cuanto a la noción de la verdad como tal, Rorty rechaza a Peirce, y se adhiere a William James. Llega a decir que perdió diez años de su vida estudiando las enrevesadas expresiones de Peirce, y que James le dio una idea de verdad abierta y más útil. Putnam da un lugar importante a James, pero también a Peirce, lo cual nos muestra que se pueden combinar los dos pensadores, para que no quede tan abierta la idea de verdad, según la frase que algunos atribuyen a James: "Verdadero es lo que me gusta". Putnam llega a una noción de verdad que admite adecuación (por la referencia), pero no tan exigente como la de los términos y enunciados como designadores rígidos que mantenía en una primera época, a semejanza de Saul Kripke (Putnam, La trenza de tres cabos. La mente, el cuerpo y el mundo, 8 ss.). Es una referencia menos rígida, menos unívoca, y, en ese sentido, más analógica. 
Hay varias nociones de verdad, pero se pueden sintetizar en tres, que corresponden a las tres ramas de la semiótica. Una es la verdad como coherencia, que corresponde a la sintaxis, como lo hizo ver Carnap; otra es la verdad como adecuación, que corresponde a la semántica, como lo hizo ver Tarski; y otra es la verdad como consenso, que corresponde a la pragmática, como lo hicieron ver Apel y Habermas.

La verdad coherentista llega a ser demasiado unívoca, idealista; a diferencia de ella, la verdad como consenso puede ser demasiado equívoca, relativista; hace falta una verdad correspondentista analógica, es decir, que no busque una correspondencia unívoca, sino analógica (por supuesto que no equívoca, porque eso no es correspondencia ninguna).

Esta verdad como correspondencia analógica coincide con la pretensión solo de verosimilitud que tiene la retórica, ya que alcanza a salvaguardar la correspondencia, la referencia, pero no es pretenciosamente unívoca, sino más abierta. De esta manera es como una noción analógica de verdad, como verdad correspondentista analógica, nos evita el peligro de relativismo que conlleva la verdad pragmática, obtenida únicamente por consenso, lo cual es muy equivocista; y también evita la pretensión positivista y neopositivista de la correspondencia unívoca. Todo ello en el camino de una pragmática analógica.

\section{Iconicidad y analogía en Peirce}

Algunos lineamientos de una pragmática analógica se encuentran ya en uno de sus célebres fundadores: Peirce. Para él, la analogía es iconicidad. Recordemos que él divide el signo en tres: ícono, índice y símbolo (Collected Papers, 2.276-284). El índice es unívoco, a fuer de signo natural, como la huella en el lodo; el símbolo es equívoco, en cuanto signo convencional, como el lenguaje, pues la mesa se dice de diversas maneras según cada lenguaje; y el ícono es análogo, en tanto que signo intermedio, híbrido, como el ícono de la justicia, que tiene cierta semejanza con lo designado, pero también depende de la cultura en la que se dé.

Asimismo, Peirce divide el ícono en tres: imagen, diagrama y metáfora (2.277). La imagen tiende a la univocidad, pero nunca la alcanza, es analógica; la metáfora tiende a la equivocidad, pero nunca incurre 
en ella, es analógica también; y el diagrama es el más analógico, pues oscila entre una fórmula algebraica y una metáfora afortunada. Estas últimas son modelos apropiados de las cosas que representan.

De esta manera, una pragmática analógica estaría muy basada en el signo icónico, en la iconicidad; tanto en la imagen, como en el diagrama y la metáfora, pues a veces tendrá la propiedad metonímica de la imagen y a veces será metáfora, o encontrará la mediación en el diagrama. Podrá oscilar entre esas tres, de manera que a veces logrará una interpretación de tipo imagen; otras, una solamente de tipo metáfora y otras de diagrama. Es decir, a veces será una imagen del texto, a veces un diagrama del mismo y a veces solo una metáfora suya.

Roman Jakobson, que era un buen conocedor de Peirce, decía que la metonimia y la metáfora son complementarias (Beristáin, Diccionario de retórica y poética, 314-315); y que ambas son los pilares del discurso humano, pues la metonimia predomina en la prosa y en la ciencia, mientras que la metáfora predomina en la poesía. Son las dos caras de la analogía, la cual, como vimos en Peirce, es la iconicidad, que también oscila entre lo metonímico y lo metafórico. Es lo analógico-icónico.

$\mathrm{Y}$ en eso consiste una pragmática analógico-icónica, que evite los dos polos extremos de la univocidad y la equivocidad. Una pragmática unívoca se quedará pretendiendo la exactitud completa en la interpretación; una pragmática equívoca se quedará hundida en una interpretación relativista y ambigua; y una pragmática analógica no renunciará a la exactitud, pero con medida, y ese mismo sentido de la medida (la phrónesis o prudencia) evitará que caiga en la equivocidad sin salida.

\section{Conclusión}

He aquí unos pocos lineamientos hacia el uso de la analogía o iconicidad en la pragmática. Hacia una pragmática analógica. No tendrá el rigor de la pragmática unívoca, pero tampoco sus inconvenientes, de ser, por ejemplo, casi nunca alcanzable, o solo en casos muy triviales. Evitará, además, los inconvenientes de la pragmática equívoca, el relativismo sin fin, pero aprenderá de ella la apertura a varias interpretaciones, que se enriquecerán mutuamente. 
Además, esta pragmática analógica ya tenía anticipaciones en los orígenes de la pragmática, sobre todo en Peirce, pero también hay aproximaciones a ella más recientes, y sigue siendo un objeto interesante de estudio.

\section{REFERENCIAS}

Apel, Karl-Otto, "Respuesta a Mauricio Beuchot", en Hermenéutica, educación y ética discursiva. (En torno a un debate con Karl-Otto Apel), Samuel Arriarán y José Rubén Sanabria (coords.), México, Universidad Iberoamericana, 1995, 67-71.

Aristóteles, Categoriae, en Opera, ed. I. Bekker, Berlin, Springer Verlag, 1961.

Beristáin, Helena, Diccionario de retórica y poética [1985], México, Porrúa, 8a. ed., 5a. reimpr., 2004.

Bertuccelli Papi, Marcella, Qué es la pragmática, trad. Noemí Cortés López, Barcelona, Paidós, 1996.

Bеuснот, Mauricio, Elementos de semiótica, México, Universidad Nacional Autónoma de México, 1979.

Bешснот, Mauricio, "The Limits of Cultural Relativism: Metaphysics and Latin America", trad. Antonio Corona y Concepción Abellán, en Cultural Relativism and Philosophy. North and Latin America Perspectives, M. Dascal (ed.), Leiden, Brill, 1991, 159-173.

Вечснот, Mauricio, "Lectura hermenéutica y pragmática", en Memorias de las Jornadas Filológicas 1996, México, Universidad Nacional Autónoma de México, 1997, 27-34.

Bечснот, Mauricio, La retórica como pragmática y hermenéutica, Barcelona, Ánthropos, 1998.

Bечснот, Mauricio, "El pensamiento analógico en las filosofías analítica y pragmática", Diánoia, 48, 2002, 25-36.

CARnAP, Rudolf, "Meaning and Synonymy in Natural Languages", Philosophical Studies, 7, 1955, 33-47.

CARnap, Rudolf, "On Some Concepts of Pragmatics", Supplement E de Meaning and Necessity. A Study in Semantics and Modal Logic [1947], Chicago-London, The University of Chicago Press, 1970, 248-250.

Carnap Rudolf y Yeoshua Bar-Hillel, An Outline of the Theory of Semantic Information, Cambridge, Massachusetts, Harvard University Press, 1952.

DASCAL, Marcelo, Pragmatics and the Philosophy of Mind, Amsterdam, John Benjamins, 1983. 
DASCAL, Marcelo, “Una crítica reciente a la noción de significado literal”, trad. Pilar van Breda Burgueño, Crítica, vol. XVIII, núm. 53, 1986, 33-55.

DASCAL, Marcelo, "Interpretazione ermeneutica e interpretazione pragmática", trad. Sergio Cremaschi, Rivista di Filosofia Neoscolastica, 79, 1987, 564579.

DASCAL, Marcelo, Interpretation and Understanding, Amsterdam, John Benjamins, 2003.

Davidson, Donald, Inquiries into Truth and Interpretation, Oxford, Clarendon Press, 1984.

DAVIDSon, Donald, "Respuesta a Mauricio Beuchot", trad. Lourdes Valdivia, en Quinto Simposio Internacional de Filosofía, Enrique Villanueva (coord.), vol. 1, México, Universidad Nacional Autónoma de México, 1992, 77-79.

ESCANDELl Vidal, María Victoria, Introducción a la pragmática, Barcelona, Ánthropos, 1993.

Grice, Herbert Paul, Significado, trad. Aline Menassé, México, Universidad Nacional Autónoma de México, 1977 (Cuadernos de Crítica, núm. 1).

Grice, Herbert Paul y Peter Frederick Strawson, "In Defence of a Dogma”, Philosophical Review, 65, 1956, 141-158.

LaudAn, Larry, "Respuesta a Mauricio Beuchot", trad. Héctor Islas, en Progreso, pluralismo y racionalidad en la ciencia. Homenaje a Larry Laudan, A. Velasco Gómez (coord.), México, Universidad Nacional Autónoma de México, 1999, 308-309.

Morris, Charles, Fundamentos de la teoría de los signos, trad. Obdulia Álvarez, Narta Santi e Irma Zangara, México, Universidad Nacional Autónoma de México, 1958.

Peirce, Charles Sanders, Collected Papers [1933], Ch. Hartshorne y P. Weiss (eds.), Cambridge, Mass., The Belknap Press of Harvard University, 1965.

Putnam, Hilary, Representación y realidad. Un balance crítico del funcionalismo, trad. Gabriela Ventureira, Barcelona, Gedisa, 1990.

Putnam, Hilary, La trenza de tres cabos. La mente, el cuerpo y el mundo, trad. José Francisco Álvarez, Madrid, Siglo XXI, 2001.

Quine, Willard Van Orman, "Two Dogmas of Empiricism”, en From a Logical Point of View, Cambridge, Mass., Harvard University Press, 1953, 20-46.

Quine, Willard Van Orman, "On what there is", en From a Logical Point of View, Cambridge, Mass., Harvard University Press, 1953, 1-19.

Quine, Willard Van Orman, Palabra y objeto, trad. Manuel Sacristán, Barcelona, Labor, 1968.

Ricoeur, Paul, "Philosophie et langage", Revue philosophique de la France et de l'étranger, n. 4, 1978, 449- 463. 
Ricoeur, Paul, "Phenomenology and Hermeneutics", Hermeneutics and the Human Sciences, John B. Thompson (ed. y trad.), Cambridge, Cambridge University Press, 1982, 101-128.

RoRTY, Richard, Contingencia, ironía y solidaridad, trad. Alfredo Eduardo Sinnot, Barcelona, Paidós, 1991.

RORTY, Richard, "El progreso del pragmatista", en Interpretación y sobreinterpretación, U. Eco (ed.), trad. Juan Gabriel López Guix, Cambridge, Cambridge University Press, 1995, 96-118.

RoRTy, Richard, "El mundo felizmente perdido", en Consecuencias del pragmatismo, trad. José Miguel Esteban Cloquell, Madrid, Tecnos, 1996, 6078.

Russell, Bertrand, "Introducción" a Ludwig Wittgenstein, Tractatus lógicophilosophicus [1922], trad. Enrique Tierno Galván, Madrid, Alianza, 1973, 11-28.

Searle, John, "Derivación de 'debe' a partir de 'ser', en Actos de habla, trad. Luis Manuel Valdés Villanueva, Madrid, Cátedra, 1990, 178-201.

Strawson, Peter Frederick, "Respuesta a Mauricio Beuchot", trad. Ana Rona, en Ensayos sobre Strawson, C. E. Caorsi (ed.), Montevideo, Universidad de la República, 1993, 181-184.

Urmson, James Opie, El análisis filosófico, trad. José Luis García Molina, Barcelona, Ariel, 1978. 